\title{
Necesidad como verdad en todo mundo posible
}

\author{
Necessity as Truth in every possible World
}

JOSÉ RUIZ FERNÁNDEZ*

\begin{abstract}
Resumen: Mi propósito es llevar a cabo una consideración fenomenológica de la noción modal de necesidad y, más en particular, del sentido cabal que puede tener la elucidación de la verdad necesaria como verdad en todo mundo posible. Las consideraciones progresan al hilo de un análisis del modo como se acredita la verdad de esas proposiciones a las que habitualmente atribuimos una necesidad no natural. Ese análisis permite fijar una noción de necesidad y del sintagma «verdad en todo mundo posible» que, pretendemos mostrar, evita algunos de los problemas que la elucidación de la noción modal de necesidad tiene en la tradición analítica.

Palabras clave: Fenomenología, necesidad, mundo posible.
\end{abstract}

\begin{abstract}
It is my intention to carry on a phenomenological consideration of the modal notion of necessity and, in particular, of the right sense in which we can elucidate necessary truth as truth in every possible world. My consideration first analyses the truth recognition of those proposition to which we usually attribute a nonnatural necessity. This analysis allows to establish a concept of necessity and of the sentence «truth in every possible world» that, we claim, solves some of the usual problems that an elucidation of modal necessity confronts within the analytical tradition.
\end{abstract}

Keywords: Phenomenology, necessity, possible worlds.

\section{Introducción}

Leibniz distinguía dos tipos de verdades. Por un lado, «verdades de razón»; por otro, «verdades de hecho». Las primeras tienen un carácter necesario y se vinculan a uno de los dos principios fundamentales que él reconocía para el pensamiento, el de no contradicción ${ }^{1}$. Una proposición es necesaria cuando el análisis indefinidamente proseguido de la misma llega a una identidad ${ }^{2}$. Esta elucidación de la noción modal de necesidad nos sirve para discriminar sobre la eventual necesidad o falta de necesidad de las siguientes proposiciones:

Fecha de recepción: 14/03/2013. Fecha de aceptación: 27/03/2013.

* Gustavo Fernández Balbuena, 32, 1 - 28002 Madrid. Correo electrónico: jose.ruiz@ filos.ucm.es Profesor Titular Interino de la Fac. de Filosofía de la UCM. Líneas de investigación: Fenomenología, Filosofía del lenguaje. Publicaciones: Sobre el Sentido de la Fenomenología. Edit. Síntesis S.A, 2008. «La indicación Formal como renovación de la fenomenología. Luces y sombras». Dianoia. Revista de filosofía. Volumen LVI, número 66, 2011, pp. 31-58.

1 Cf. Leibniz, G.W. Monadología, Ed. Alhambra, Madrid, 1990, n.33-35.

2 Cf. Leibniz, G.W., Sämtliche Schriften und Briefe. Deutsche Akademie der Wissenschaften zu Berlin. Darmstadt, 1923, VI, Vol. iv, p.1650. 
a) Wittgenstein nació en Europa.

b) Cualquier hombre necesita más de 3 segundos para recorrer un kilómetro a pie.

c) Si todo hombre es bípedo y Einstein es un hombre, Einstein es bípedo.

En efecto, reconocemos, siguiendo lo anterior, que lo aseverado en a) no es necesario; que b) enuncia algo verdadero por las características empíricas del hombre, por naturaleza, pero no por gracia del principio de contradicción; y que sólo c) es necesario en ese sentido.

Ahora bien, aunque dejáramos fuera de consideración la «necesidad natural», lo cierto es que seguiríamos considerando necesarias otras proposiciones cuya negación no parece ser contradictoria. Por ejemplo: «algo coloreado es extenso», «un sonido tiene alguna intensidad», «la suma de los ángulos de un triángulo es de 180 grados». No es pues tan claro que sea lo mismo que una proposición sea verdad necesariamente y que una proposición sea verdad por gracia del principio de no contradicción lógica (al menos mientras éste no se extienda más allá de lo que habitualmente cubre).

Ciertas alusiones en la obra de Leibniz a mundos posibles se han tomado recientemente como un germen de la idea, que no se encuentra en el propio Leibniz, de que la noción de verdad necesaria se podría elucidar en términos de verdad en todo mundo posible. Algo imposible sería, según esto, algo que ha de ser falso en todo mundo posible, y algo contingente sería algo que podría ser verdadero o falso en algún mundo posible. Se entiende bien que esta apelación a mundos posibles haya parecido prometedora en aras a aclarar qué es lo que comprende esa noción modal de necesidad que parece desbordar la mera contradicción lógica. Por un lado, la reformulación parece simple e intuitiva. Cuando se dice que algo es necesario no parece que se diga otra cosa que eso es verdad... «con independencia de todo» ${ }^{3}$. Por otro, ella parece excluir sin ambages esa «necesidad natural» que se concede sólo porque suponemos que lo que fácticamente ocurre se mantendrá dentro del orden en que se nos ha presentado. No es inimaginable que un hombre corriera a la velocidad que contradiría el aserto b) anteriormente consignado: el mundo podría ser de tal manera que tal cosa fuera posible. Luego eso no es necesario. Finalmente, parece que la reformulación se aviene bien a esa necesidad que no parece deberse a la mera ausencia de contradicción lógica: algo coloreado seguiría siendo extenso en todo mundo imaginable.

Pero el optimismo no está tan legitimado como a primera vista pudiera parecer. En relación a los aparentes logros que se acaban de aducir, cabría objetar: ¿Cómo se sabe que una criatura que corriera a una velocidad ilimitada seguiría siendo un hombre? ¿Es conciliable con ser un hombre la capacidad de volar y tener escamas? ¿Tiene acaso el hombre una esencia que garantice su identificación inequívoca en mundos posibles diferentes? ¿Cómo adoptar aquí un criterio sin caer en un injustificado esencialismo? Por otra parte, ¿por qué hay que considerar imposible un mundo donde algo coloreado no tuviera extensión alguna? ¿No se ha mantenido como algo necesario que la suma de los ángulos de un triángulo era de 180 grados y, sin embargo, se ha llegado a creer que la geometría euclidiana no se aplica en nuestro mundo físico? ¿Cómo poner coto entonces a lo que fácticamente cabe y no cabe en un mundo posible? ${ }^{4}$

3 Cf. Quinton, A., «The a priori and the analytic», en Strawson, P.F. (ed.) Philosophical Logic, Oxford, Oxford University Press, 1967, pp.109-110.

4 Para una breve pero precisa presentación de estos problemas Cf. Grayling, A.C., An Introduction to Philosophical Logic, Duckworth, Alden Press, Oxford, 1990, pp.68-90. 
El caso es que no sabemos bien cómo debe entenderse nuestra apelación a mundos posibles para que tenga buen sentido identificar algo necesario y algo verdadero en todo mundo posible. Pero esto quiere decir que lo que aparentemente parecía un logro de claridad nos está devolviendo a la cuestión inicial: ¿en qué sentido hablamos de necesidad —en sentido no natural - y a qué se puede deber tal necesidad? El propósito de este texto es enfrentarse a estas cuestiones. Se trata, por tanto, de poner de relieve qué es lo que hace que una proposición involucre necesidad. A la vez, se trata de precisar cómo debe entenderse el sintagma «verdadero en todo mundo posible» de manera que, sin caer en el esencialismo ni en prejuicios empírico-fácticos, sirva para elucidar nuestra comprensión inmediata de la modalidad de necesidad.

Para hacer esto se va a seguir el siguiente camino. Primeramente se va a hacer una consideración fenomenológica de la evidencia que tenemos de algunas proposiciones que involucran necesidad y, en particular, de la proposición que dice que algo coloreado es extenso. A partir de esas consideraciones se podrá precisar algo inherente a toda evidencia de algo necesario y, con ello, en qué sentido se puede identificar verdad necesaria y verdad en todo mundo posible. Finalmente, se defenderá que la comprensión de la necesidad presentada preserva su carácter absoluto sin caer en la falacia del esencialismo.

Antes de empezar conviene precisar qué entendemos aquí por evidencia. En la tradición analítica la expresión 'evidencia' ${ }^{5}$ se usa primariamente para referirse al material empírico que habla en favor de un aserto. Por evidencia se entiende aquí algo similar, pero en un sentido ampliado, que no se limita a lo empírico. La evidencia de una proposición es, para nosotros, la experiencia que da legitimidad a la proposición, esto es, la experiencia, empírica o no, que funda su verdad. O dicho con otras palabras, la evidencia de un aserto es la experiencia en la que se reconoce la verdad de ese aserto. Un ejemplo puede ayudar a entender lo que estoy tratando de decir. Se puede afirmar en medio de una conversación que $1+2=3$ sin advertir la verdad de lo que se asevera. En un segundo momento se puede, sin embargo, evidenciar que $1+2=3$, esto es, reconocer la verdad de lo que se había afirmado confiadamente. Nada hay de extraño o místico en ese reconocimiento. Para que el lector se dé cuenta de la diferencia entre aseverar una proposición y reconocer la verdad de una proposición, basta con que deje de leer un momento estas líneas y advierta efectivamente que es verdad que uno más dos es necesariamente igual a tres. Por lo demás, no suponemos que ese reconocimiento sea un proceso mental. Entendemos que la evidencia es la experiencia misma del reconocimiento de la verdad de una proposición con independencia del modo como esa experiencia sea ontológicamente caracterizada ${ }^{6}$.

5 Se usarán comillas simples para nombrar una expresión tipo. Las comillas dobles se usan de la manera habitual y, particularmente, para nombrar una expresión con significado.

6 La fijación terminológica de la evidencia en su irreductibilidad experiencial es deudora de Husserl, obviamente, y, en particular, de la VI Investigación Lógica (Cf. Husserl, E., Husserliana XIX/2, The Hague/Boston/Lancaster, Martinus Nijhoff, 1984, p.652). Se prescinde aquí, en todo caso, del marco teórico problemático desde el que Husserl se hizo cargo de esa experiencia. 


\section{Una historia y un problema}

Queremos caracterizar lo que sucede al evidenciar algo necesario. Nuestras consideraciones progresarán tomando como hilo conductor el análisis de la evidencia que tenemos de que algo coloreado es extenso ${ }^{7}$.

Pongámonos en situación para captar esa proposición cuya evidencia hay que considerar. Es posible que algo coloreado no pueda ser experimentado de manera táctil, como sucede tratándose de una nube o de un arco iris. Sin embargo, algo coloreado exhibe siempre una superficie y, en este sentido, es visualmente extenso. El color dado va de la mano con la superficie que ocupa. Convenimos, por tanto, sin mucho problema en que algo coloreado es necesariamente extenso. Asumimos, incluso, que no es difícil evidenciar eso. Con todo, voy a contar a continuación una pequeña historia que usaré para desafiar nuestra comprensión de lo que sucede en esa evidencia.

Un niño nace ciego. Sus padres, movidos por un instinto de protección mal orientado, piensan que la criatura vivirá más feliz si no se da cuenta de su tara física. Deciden recluirlo en casa, aislándolo de otras personas, a la vez que le ocultan su discapacidad.

Los padres educan al niño de la mejor manera que pueden. Celosos de proteger su autoestima, sólo una cosa omiten con admirable disciplina: nunca utilizan en su presencia términos vinculados a la visión. 'Ver', 'vista', 'oscuridad', 'luz', 'color', 'ceguera'... son expresiones proscritas, que el muchacho no debe oír. Los padres adaptan no sólo su discurso, sino también su comportamiento a las posibilidades del niño. Le proporcionan figurillas de madera para que pueda ligar a una experiencia intuitiva muchas de las palabras que le introducen. Incluso le enseñan a leer siguiendo un sistema de signos. El infante va creciendo sin conciencia del abismo que separa su mundo y el de sus progenitores, únicas personas con las que tiene trato. Por lo demás, las habilidades verbales del niño son tan agraciadas, que su gramática, dicción y, salvo en el respecto apuntado, vocabulario, pueden competir con los de cualquier niño de su edad. Por supuesto, utiliza con soltura y eficacia expresiones como 'espacio', 'superficie', 'extensión', 'lejos', 'cerca'... aunque lo hace sin contar con la vertiente visual que esas palabras tienen para nosotros.

El muchacho va madurando. Como los padres tienen afición por la filosofía, la lógica y las matemáticas, adaptan algunos textos para que pueda leerlos. Por su carácter abstracto pueden ser purgados mejor del léxico indeseable. El joven muestra curiosidad por estas materias. Avanza con rapidez en la lógica y en el cálculo. De la filosofía le entusiasman los problemas vinculados a la necesidad. A los 18 años hace saber a sus padres que ha encontrado algo necesario de lo que sus lecturas nunca le habían dado noticia.

— ¿Qué?, le preguntan intrigados.

-Que un objeto con una superficie es necesariamente táctil, responde el joven. Hay cosas espaciales, como los sonidos, que no pueden tocarse, pero es imposible que algo con una superficie extensa no sea táctil. Si algo tiene una superficie eso se debe, justamente, a que puede ser exhibido táctilmente. La cosa es clara.

7 Lo que aquí se va a decir tiene puntos en común con el modo como Husserl piensa la evidencia de eso que él llamaba un «a priori material», pero también divergencias importantes que oportunamente se apuntarán. 
Sus padres se quedan desconcertados. Se dan cuenta de que no pueden rebatir lo que su hijo dice sin abandonar las pautas discursivas que con él mantienen. No pueden decirle que una nube exhibe una superficie, por mucho que no se pueda tocar. No pueden hablarle de superficies visuales. Felicitan, por tanto, a su hijo, y no se atreven a discutirle su hallazgo. El niño lo atesora durante toda su vida: para él no deja de ser evidente que algo con una superficie es necesariamente táctil.

El relato que se acaba de contar ha referido algo que parece posible. Pero, por eso mismo, resulta inquietante. Cuando el muchacho ciego dice 'algo con una superficie es necesariamente táctil' utiliza la expresión 'algo con una superficie' de tal manera que eso que afirma es para él evidente. Tan evidente como para nosotros pueda ser que algo coloreado es necesariamente extenso. La legitimidad que tenemos nosotros para afirmar esto último no es mayor que la que él tiene para afirmar lo primero. Y esto parece sorprendente pues, a todas luces, algo con una superficie no es, para nosotros, necesariamente táctil. Lo que este relato ha puesto de relieve debe ayudarnos a reflexionar acerca de lo que ocurre al evidenciar que algo coloreado es necesariamente extenso.

Probablemente el lector pensará que lo que el relato ha puesto de relieve es que una evidencia de algo necesario depende del significado de las expresiones que empleamos en nuestro aserto. Porque la expresión 'superficie' es usada por el muchacho ciego sólo por relación a lo táctil, y no por relación a lo visual, lo que él significa con esa expresión es distinto de lo que nosotros significamos con ella. Por esa razón, no es extraño que cambie lo que él y nosotros reconocemos como necesariamente asociado a «algo con una superficie». Igualmente, nuestra expresión 'color' podría cambiar su significado de modo parecido, es decir, de modo que no sólo se aplicara a lo cromático-visual sino también a algo distinto, viéndose así modificado lo que reconocemos necesariamente vinculado a 'algo coloreado' . La contradicción entre lo que él sostiene y lo que nosotros sostenemos es, por tanto, sólo aparente: en realidad, lo que en cada caso decimos y evidenciamos son cosas distintas pues ha cambiado el significado de las expresiones empleadas. Todo esto es correcto. Sin embargo, falta por considerar algo decisivo menos fácil de advertir. Para lograrlo, llevaremos a cabo una consideración más directa de lo que pasa al evidenciar que algo coloreado es necesariamente extenso. Pero antes, hay que poner de relieve una cierta diferencia en el modo como se evidencian ciertas proposiciones característicamente necesarias.

\section{Dos modos de evidenciar algo necesario}

Si alguien nos preguntara si el rojo es necesariamente un color le daríamos una respuesta afirmativa sin dudarlo. Si nos preguntara cómo lo sabemos, no nos sería tan sencillo encontrar algo que decirle. Que el rojo sea necesariamente un color no quiere decir que siempre que se utilice la expresión 'rojo es un color' se esté diciendo algo verdadero. Esa misma expresión podría usarse para aseverar algo patentemente falso. Rojo es necesariamente un color porque esto que aseveramos (con expresiones que podrían cambiar) se acredita al ponerse de relieve que a algo significado («rojo») le es inherente «algo» (ser un color). Esta acreditación, que no es la mera aseveración, es la evidencia de la proposición aseverada. La evidencia de una proposición y la proposición evidenciada no pueden entenderse como dos cosas independientes: una evidencia es lo que es como acreditación de la verdad de una 
cierta proposición. Tenemos legitimidad para enunciar «rojo es necesariamente un color» porque la proposición aseverada con esas palabras es aquella que acredita su verdad en la evidencia antes apuntada. Al lector no le costará mucho recrear esa evidencia. Como no le costará evidenciar que $1+1=2$.

Si consideramos lo que sucede en la experiencia en la que se acredita la verdad de esas proposiciones, esto es, en la evidencia de esas proposiciones, podemos darnos cuenta de que lo acreditado es algo necesario porque es algo operacionalmente construido. Para ilustrar esto consideremos, a modo de ejemplo, lo que ocurre en la evidencia de que $1+1=2$.

Podemos decir de corrido que uno y uno son dos asumiendo que tal cosa es cierta. No es lo mismo, sin embargo, contar con la verdad de una proposición, o estar acostumbrado a aseverar una proposición, que tener evidencia de una proposición. De hecho, lo primero es lo que hace considerarnos dispensados de tener que hacer lo segundo. Que uno más uno es dos no se acredita porque se pueda mostrar empíricamente que al proferir la expresión 'uno más uno es dos' los hablantes de español suelan asentir. Sabemos que uno más uno es dos porque la proposición que aseveramos es aquella que encuentra su acreditación al identificar la posición sucesiva de algo y algo, en tanto que pluralidad, como dos. Ahora bien, esta es una forma de evidencia particular. Al evidenciar que uno más uno es dos se pone algo y se pone otro algo; volviendo sobre esta posición sucesiva como pluralidad la determinamos (dos); ahora bien, como esa pluralidad (dos) es lo que es por relación al poner sucesivo de algo y algo (uno más uno), se advierte que uno más uno es dos en ese modo particular de «no poder sino ser así». Que uno más uno sea dos es necesario porque la identidad aseverada en esa proposición es tal que encuentra su evidencia en una composición operacionalmente construida o, podemos decir también, auto-contenida. Esto mismo pasa cuando se evidencia que rojo es un color. Acreditamos que rojo es un color dándonos cuenta de que a algo significado («rojo») le es inherente «algo» (ser un color). Pero ese «ser inherente» no es algo que se acredite al margen de lo significativamente concernido en la proposición aseverada («rojo» $\mathrm{y}$ «ser un color»): es una articulación interna del sentido de las expresiones involucradas en nuestra aseveración. Por eso mismo no advertimos algo fáctico, sino que rojo es necesariamente un color.

Llamamos ahora la atención sobre un segundo rasgo característico de la evidencia de esas dos proposiciones que venimos considerando. Adviértase que en los dos casos la evidencia puede darse sin representarse nada imaginativamente. Aunque al evidenciar que el rojo es un color podamos imaginar algo de color rojo, no hay necesidad de ello. Podemos advertir que a algo significado («rojo») le es inherente «algo» (ser un color) sin necesidad de representarnos nada rojo. De la misma manera, al evidenciar que uno más uno es dos, quizá imaginemos un árbol y otro árbol. O cualquier otra cosa. Pero no tenemos por qué. Ni esa evidencia depende en absoluto de lo que nos hayamos podido representar.

Ahora pasemos a considerar qué pasa cuando se evidencia que algo coloreado es extenso.

Convenimos enseguida que algo coloreado es necesariamente extenso. Pero quizá lo hacemos desde esa seguridad con la que se revisten los lugares comunes. Confiar, o contar con que algo coloreado es extenso no es acreditar la verdad de esa proposición, es decir, tener evidencia de ella. Lo que nos interesa ahora es esa evidencia en su ocurrencia efectiva. Pues bien, adviértase que no podemos evidenciar que algo coloreado es extenso de la manera como evidenciamos que rojo es un color. Tomado como algo meramente significado, «algo 
coloreado» no cae bajo «algo extenso». «Algo coloreado» no se relaciona con «ser extenso» o «no ser extenso» de la manera como «rojo» se relaciona con «ser color». Algo coloreado puede acreditarse como siendo extenso sólo en presencia de algo coloreado. Pero, siendo esto así, ¿cómo podrá ser posible llegar a evidenciar que algo coloreado es necesariamente extenso?

En este punto no se trata de argumentar nada. El lector tiene que procurarse esa evidencia, es decir, debe sustraerse al asentimiento mecánico de que algo coloreado es necesariamente extenso y acreditar su verdad. ¿Cómo se logra esto? Imaginamos algo coloreado. Puede ser un árbol, puede ser una figura indeterminada. No importa. Nos damos cuenta de que ello es algo extenso. Probamos ahora a variar su extensión, y advertimos que si la extensión se hace nula, no podemos ya representarnos algo coloreado. Advertimos que algo coloreado tiene que ser extenso, esto es, que la presencia de algo coloreado involucra constitutivamente extensión. Si el lector prueba a evidenciar eso mismo sin recurrir a la imaginación se dará cuenta de que no es posible. Sin embargo, esto es sorprendente. ¿Cuál es la razón de que algunas proposiciones evidencien su verdad necesaria al hilo de cierto proceso en la imaginación?

\section{Lo que hay de peculiar en esta evidencia}

Después de contar nuestro relato se dijo que una manera de dar razón de que el muchacho ciego se encontrara legitimado para decir 'algo con una superficie es necesariamente táctil' consistía en apuntar que el significado que para él tiene la expresión 'superficie' es distinto del que tiene para nosotros. Aunque eso es correcto, explica sólo una parte de la cuestión.

Supóngase que la expresión 'rojo' pasara a usarse como habitualmente usamos la expresión 'perro'. Y supóngase que la expresión 'perro' pasara a usarse como habitualmente usamos la expresión 'rojo'. Con ello la expresión 'rojo es un color' no se utilizaría para aseverar algo que pudiera evidenciarse, y la expresión 'perro es un color' sí. Todo esto no modificaría nuestra evidencia de que rojo es necesariamente un color, sino sólo la manera como expresamos la proposición evidenciada. Ahora preguntémonos si este tipo de cambio es todo lo que debería ocurrir para que el muchacho ciego de nuestro relato pudiera evidenciar que algo con una superficie no es necesariamente táctil. No parece. De la misma manera que para evidenciar que algo coloreado es necesariamente extenso hay que hacerse cargo imaginativamente de las posibilidades que caben para algo coloreado, hay que caer en la cuenta imaginativamente de que una superficie puede ser visual para evidenciar que una superficie no es necesariamente táctil. Pero el muchacho de nuestro relato no podrá nunca hacer esto. Sus expresiones podrían modificarse arbitrariamente y sus recursos léxicos ampliarse, pero ningún cambio de este tipo le permitiría evidenciar que algo con una superficie no es necesariamente táctil. Él, simplemente, no puede imaginarse superficies visuales. Para que el muchacho ciego pudiera evidenciar eso como nosotros lo hacemos no basta con un mero cambio léxico-significativo, sino también un cambio en la dimensión de mundo en que significativamente usa sus expresiones. Consideremos esto con algo de detenimiento, porque es menos sencillo de lo que parece.

El muchacho ciego, ciertamente, no puede evidenciar que algo coloreado es necesariamente extenso. Más aún, de hecho ni siquiera puede formular esa proposición. Para 
poder decir lo que nosotros decimos significativamente con la expresión 'algo coloreado es extenso', debería estar empleando significativamente la expresión 'color' por relación a lo mismo que a nosotros nos concierne cuando hablamos significativamente de un color. El significado de las expresiones 'rojo', 'color', 'algo coloreado' o 'superficie extensa' va de la mano, efectivamente, con el mundo en el que se aplican, esto es, con lo que en cada caso nos concierne en su uso, con lo que en cada caso discriminamos. Así, cuando el muchacho ciego utiliza significativamente la expresión 'superficie', lo que dice entonces tiene que ver con una cierta experiencia cinestético-táctil, pero no con un campo visual. Hablando en términos de significado podemos decir: lo que para él significa 'superficie' no puede separarse de lo que con ello va concernido en su dimensión de mundo. Pues bien, caracterizaremos el hecho de que el significado de una expresión involucra la posible aplicabilidad en una dimensión de mundo diciendo que al significado de una expresión es inherente un arraigo en un mundo. Ésta es una terminología técnica que adoptaremos a partir de ahora.

$\mathrm{Si}$ el significado puede involucrar un arraigo en nuestro mundo puede que, después de todo, no sea tan sorprendente que el reconocimiento de la necesaria verdad de una proposición en cuya formulación aparecen las expresiones 'A' y 'B' dependa de la exhibición de las posibilidades que caben para A y B en ese mundo en cuyo arraigo se están usando significativamente las expresiones 'A' y 'B'. Esto es lo que sucede en el caso que estamos considerando. Veámoslo.

Lo peculiar de la evidencia de que algo coloreado es extenso estriba en que esa evidencia consiste en darse cuenta de las posibilidades involucradas en aquello de lo que se está tratando en tanto que nuestro significativo tratar sobre ello arraiga ya en un mundo. Precisemos esto. Cuando se trata de evidenciar que algo coloreado es necesariamente extenso empezamos por ejemplificar imaginativamente algo coloreado. Lo imaginado es de entrada algo coloreado, esto es, no cualquier cosa, sino un caso de aquello de lo que significativamente tratamos. En tanto que «algo coloreado» es lo que es en un arraigo de mundo, al mantenernos imaginando algo coloreado va comprendido ya de qué va la cosa, es decir, lo que cabe y no cabe en concreto, esto es, las posibilidades en que lo imaginado se puede mover. En un segundo momento, nos damos cuenta de que lo que imaginamos es extenso. $\mathrm{Y}$ entonces, en un tercer momento, advertimos que la eliminación de su extensión no permitiría seguir imaginando algo coloreado. Es decir, advertimos que no puede conciliarse algo coloreado y algo sin extensión dentro de las posibilidades que caben para aquello de lo que estamos tratando. Darse cuenta imaginativamente de las posibilidades que caben para algo coloreado y algo extenso es darse cuenta de qué es lo que concretamente cabe y no cabe dado el arraigo de mundo inherente a las expresiones significativas «algo coloreado» y «algo extenso».

Un comentario se impone. La posibilidad de evidenciar una verdad necesaria como $1+1=2$ o rojo es un color se comprende bien porque nos damos cuenta de que lo que ahí se está expresando no es nada más que un vínculo o relación que se deja construir operacionalmente. Por esa razón, a primera vista parece sorprendente que una evidencia de algo necesario tenga que recurrir a un proceso imaginativo. La extrañeza inicial se mitiga al advertir que la evidencia depende aquí, no de lo imaginativamente representado, sino de lo operacionalmente desplegado al hilo del proceso imaginativo. Para darnos cuenta de que al eliminar la extensión de algo se pierde la posibilidad de venir dado algo coloreado, conju- 
gamos en la imaginación las posibilidades abiertas para algo coloreado y algo extenso dado el arraigo mundano propio de nuestro significar «algo coloreado» $\mathrm{y}$ «algo extenso». En otras palabras: llevamos a cabo una exhibición explícita de las posibilidades concretas inherentes a nuestro decir arraigado. Y la evidencia que al hilo de ese despliegue se realiza es un darse cuenta de las posibilidades que caben para aquello de lo que significativamente ya estamos tratando. Esa evidencia es, por tanto, también aquí, la explicita construcción operacional de una relación. La evidencia de que rojo es un color o de que $1+1=2$ se diferencia de la evidencia de que algo coloreado es extenso, no en que en un caso la evidencia dependa de una composición auto-contenida y en el otro no, sino en que en el segundo caso esa composición se realiza en un construcción operacional de distinto carácter.

En general, se puede decir que una verdad es necesaria cuando la acreditación de esa verdad ha de ocurrir en la forma de una composición operacional auto-contenida. Lo que estamos diciendo se aviene bien con el hecho de que incluso cuando no tenemos evidencia de la verdad de una proposición, o no somos capaces de tenerla, es posible saber que en caso de que sea verdadera, se tratará de una verdad necesaria. Considérese, por ejemplo, la conjetura de Goldbach, o la conjetura de que jugar con piezas blancas es una ventaja suficiente en principio para ganar en el ajedrez. No sabemos si eso es verdad. Sabemos, sin embargo, que cualquier acreditación de la verdad de esas proposiciones se dará en la forma de una explicitación de las posibilidades abiertas en un orden de articulación cerrado. Sabemos, por tanto, que esas conjeturas o sus negaciones habrán de ser necesariamente verdaderas. Lo que aquí estamos proponiendo se asemeja a la profunda idea de Leibniz de que una proposición es necesaria cuando el análisis indefinidamente proseguido de la misma llega a una identidad. Pero habría que matizar. Por una parte, la evidencia de algo necesario no se funda en el análisis sino, en todo caso, es ella la que lleva a advertir que una cierta paráfrasis o análisis del significado de las expresiones es cabal. Por otra parte, no se llega aquí a una identidad lógica en el sentido que habitualmente se vincula con la contradicción. El plano lógico en sentido tradicional no es aquí lo decisivo.

\section{Facticidad y mundos posibles}

Aunque las reflexiones precedentes se hayan orientado a caracterizar la evidencia propia de que algo coloreado es necesariamente extenso, obviamente no es esa evidencia singular lo que interesaba, sino el tipo. Si no me equivoco, de esa manera se evidencian algunas de las proposiciones que Kant llama sintéticas a priori ${ }^{8}$. De esta misma manera se evidencian, también, muchas de las proposiciones que en la fenomenología de Husserl se supone expresan un a priori material ${ }^{9}$. Ahora bien, hablar en esos casos de un conocimiento a priori es,

8 Cf. Kant, I., Prolegómenos a Toda Metafísica Futura que Haya de Poder Presentarse como Ciencia, Madrid, Istmo. 1999, §6-11. Como se ha visto, sin embargo, nada parecido a una forma pura de la sensibilidad o del entendimiento ha hecho falta suponer para comprender la acreditación de la proposición considerada.

9 Cf. Husserl, E., Experiencia y Juicio, México, Universidad Nacional Autónoma de México, 1980, p.390. Nuestra exposición guarda una discrepancia importante con el pensamiento de Husserl. Un juicio universal necesario del tipo algo coloreado es extenso dependería, para Husserl, de la previa intuición esencial del concepto puro «algo coloreado». La ideación o método de contemplación de esencias es, para Husserl, un proceso en el que se destacaría el invariante esencial inherente a una serie de particulares representados en variación libre. La aprehensión intuitiva del eidos es, aquí, un rendimiento constituido sobre la base de esas representaciones 
cuando menos, confuso. Precisaremos a continuación en qué sentido se puede decir que la acreditación de algo necesario es independiente de elementos fácticos.

¿Es verdadero a priori que algo coloreado es extenso? ¿Qué quiere decir a priori? El término 'a priori' tiene para nosotros un carácter epistemológico, es decir, lo usamos para caracterizar la manera de conocer algo. Que algo se conoce a priori significa, más o menos, que llega a ser conocido con independencia de cuestiones de hecho. Según esto, podría pensarse que no sabemos a priori que esa proposición es verdadera ya que su acreditación involucra un elemento fáctico, a saber, el darse cuenta de las posibilidades que caben para aquello de lo que tratamos habida cuenta de que al tratar significativamente sobre ello va involucrado un arraigo de mundo. Y, sin embargo, desde otra perspectiva, sería insatisfactorio decir que ese conocimiento se obtiene a posteriori. Lo que nos mueve a decir que conocemos a posteriori que ahora está lloviendo es distinto de lo que nos podría mover a decir que conocemos a posteriori que algo coloreado es necesariamente extenso. En el primer caso hay un conocimiento que depende de la constatación de algo fáctico. En el segundo, no. Que algo coloreado es necesariamente extenso se acredita en la exhibición operacional de las posibilidades abiertas a algo coloreado dado el arraigo de mundo en el que se mantiene nuestro decir. El arraigo significativo en nuestro mundo va involucrado en ese proceso cognoscitivo, pero no la constatación de algo fácticamente dado. En vez de hablar de a priori sería preferible decir, entonces, que el conocimiento de algo necesario no depende de la constatación de algo fáctico, esto es, de algo que de una u otra manera se nos ofrezca por sí mismo con independencia del proceso evidenciante. Esa facticidad debe entenderse aquí en un sentido amplio, sin limitarla a la percepción sensible. Si tras afirmar «tengo 41 años» refiero después que acabo de enunciar algo, constato fácticamente algo, aunque no algo sensiblemente percibido. Por contraposición a esto, que algo coloreado es extenso no es un aserto cuya acreditación dependa de algo fácticamente dado, sino de algo operacionalmente construido. Si, como se ha apuntado, una verdad necesaria es una que se acredita en una construcción operacional auto-contenida, entonces cabe decir que el proceso cognoscitivo en el que se acredita una verdad necesaria no involucra constataciones fácticas, aunque sí pueda involucrar el arraigo significativo en el mundo que habitamos.

No se trata, por tanto, de que nuestro mundo no se vea involucrado en el proceso cognoscitivo que lleva a evidenciar una verdad necesaria, sino de que la verdad de lo que evidenciamos es independiente de toda facticidad. ¿Pero cómo puede ser esto? ¿Cómo puede

(Husserl, E., 1984, op.cit., pp.690-1; Husserl, E., 1980, op.cit., p.379). Este enfoque de la cuestión esconde, en mi opinión, un error: no es que la aprehensión del eidos se edifique sobre la base de las presentificaciones de lo particular, sino que la variación de lo particular es la que es en tanto que sujeta a aquello de lo que significativamente ya se trata. La ideación no rinde tanto la intuición de un eidos, cuanto una explicitación de las posibilidades concretas que caben en aquello de lo que significativamente ya estamos tratando. El matiz es importante. En la medida en que Husserl obvia que el proceso de la ideación se despliega sobre el fondo del significado lingüístico hay una tendencia a presentar esa ideación como un método con el que accedemos a una esencia real, esto es, como una vía que sirviera para descubrir o acceder a una estructura originaria. Esto mismo anima a que la evidencia de que algo coloreado sea necesariamente extenso tienda a asumirse como una acreditación de una ley a la que se ordenara a priori la realidad. No hay, sin embargo, tal. Constatamos que algo coloreado es necesariamente extenso en un despliegue operacional que supone el arraigo significativo en un mundo. Hay, ciertamente, constatación de algo necesario, pero en modo alguno descubrimiento de una ley esencial que hubiera prefigurado de entrada la realidad. 
ser que la acreditación de una verdad dependa de nuestro mundo fáctico y, sin embargo, la verdad acreditada sea independiente de toda facticidad? Aclarar esto mejor nos ayudará a entender cuál es el sentido cabal en el que se puede decir que algo necesariamente verdadero es algo verdadero en todo mundo posible.

Al preguntarnos si algo coloreado es necesariamente extenso con independencia de cuestiones fácticas preguntamos en nuestro propio decir significativo. Pero ese decir significativo es el que es en el arraigo de una dimensión de mundo. Esto quiere decir que lo que queda concernido en esa pregunta se mantiene de entrada en el arraigo de mundo que es propio a nuestro significar. Pero entendamos esto bien. No es que, desde fuera, constriñamos las posibilidades para aquello de lo que hablamos. Se trata de que aquello de lo que se está hablando es lo que es en el arraigo de mundo en el que significativamente nos mantenemos hablando, de manera que fuera de ahí no hay cuestión acerca de la verdad o no verdad de nada. Yo puedo pensar que es posible un mundo distinto que no me puedo representar, y que en ese mundo alguien puede estar utilizando los términos 'color' y 'extensión' de una forma que me es extraña, y que en esos usos y en ese mundo la expresión 'algo coloreado no es extenso' podría proferirse para realizar una proposición verdadera que yo no puedo ni realizar ni evidenciar. Todo eso es posible. Lo que no es posible es que algo coloreado pudiera no ser extenso en otro mundo. Esto que ahora digo lo digo desde el decir que es el mío. Por relación a eso que digo, no a otra cosa, en el arraigo de mundo en que mi decir se mueve, no en otro, evidencio que algo coloreado es extenso necesariamente. Ciertamente, conozco esa verdad desde un significar arraigado en un mundo fáctico. Pero esa verdad que conozco, al hilo de una construcción operacional, no es relativa a mi mundo fáctico.

Supongamos ahora que lo que se pretendiera afirmar al decir que algo es verdad en todo mundo posible es que hay una expresión cuya verdad trasciende nuestro mundo y nuestro lenguaje. Entonces «algo coloreado es necesariamente extenso» no sería verdad en todo mundo posible. Pero es que así tampoco lo sería «un árbol es un árbol» o «uno más uno es dos». Hablar acerca de la verdad, posibilidad y necesidad de algo tiene sentido en nuestro decir significativo, no en otro sitio. Desde ese decir arraigado evidenciamos que algo coloreado puede ser rojo o verde, que puede tener forma cuadrada o triangular, pero que es necesariamente extenso. Dicho de otra manera: evidenciamos que algo coloreado es extenso con independencia de toda cuestión fáctica, en todo mundo posible. Lo que no evidenciamos nunca es que una particular expresión enuncia algo verdadero en todo mundo posible.

Si el sintagma «algo verdadero en todo mundo posible» ha de poder entenderse como equivalente de «algo necesariamente verdadero», entonces aquel sintagma debe asumirse en el sentido de algo verdadero con independencia de toda facticidad, esto es, con independencia de cuestiones de hecho ajenas al proceso evidenciante.

\section{Una necesidad absoluta... en el sentido en que ha sido evidenciada}

Si algo necesario se evidencia entonces ello es verdad en todo caso, con independencia de constataciones fácticas, porque se evidencia operacionalmente en un proceso auto-contenido. La idea de una verdad definitiva, irrevisable, ha sido resistida por algunos 
pensadores, entre ellos Quine ${ }^{10}$. A los ojos de Quine nuestras creencias forman una red o sistema que sólo periféricamente incide en la experiencia. En principio, una experiencia recalcitrante lleva a cambiar sólo aquella parte de nuestras creencias que están en la periferia, pero no el núcleo central de nuestra red de creencias. Sin embargo, esta diferencia es sólo de grado. En principio, cualquier creencia o idea podría ser revisada, incluso las que se expresan en las leyes lógicas. De esta manera, se ha cuestionado que haya algo así como verdades necesarias.

El pensamiento que se acaba de expresar admite una fácil ejemplificación. Piénsese en toda la geometría Euclidiana. Durante siglos ella ha sido tenida por una verdad necesaria. Sin embargo, podría pensarse, la matemática moderna, al axiomatizar otras geometrías igual de consistentes que la Euclidiana, y el desarrollo de la física, al hacer uso de esas geometrías, han puesto de relieve que la necesidad que concedíamos a la geometría Euclidiana era sólo presunta. A continuación se hará una reflexión sobre este caso a fin de mostrar el error que se esconde tras esta forma de argumentar. Sostenemos, en efecto, que la necesidad que antes se ha elucidado es absoluta. Sostenemos, en otras palabras, que si se evidencia algo necesario entonces la verdad que ahí se acredita es irrevisable, definitiva.

El proceder habitual para acreditar la verdad de las proposiciones expresadas en la geometría Euclidiana descansa en construcciones operacionales del tipo que se ha glosado en nuestras consideraciones. Por ejemplo, evidenciamos que los ángulos de un triangulo suman necesariamente 180 grados en una serie de pasos en los que, al hilo de ciertos casos intuitivamente representados, hay que advertir imaginativamente qué posibilidades caben para un triángulo, una paralela, un ángulo... Adviértase, por lo pronto, que esa evidencia no podría recusarse aduciendo que los ángulos de los «triángulos» esféricos suman más de 180 grados. Los triángulos esféricos no son triángulos en el sentido en que nosotros decimos que los ángulos de un triángulo suman necesariamente 180 grados. Cuando el muchacho ciego de nuestro relato decía 'algo con una superficie es necesariamente táctil' expresaba algo que no se puede recusar alegando que esas superficies pueden ser visuales. Esas superficies de las que él habla no pueden ser visuales porque aquello de lo que él está hablando usando la expresión 'superficie' no tiene nada que ver con superficies visuales. De la misma manera, cuando se advierte que los ángulos de un triangulo suman 180 grados no se está evidenciando que eso sea verdad por relación a toda proposición que pudiera formularse con las expresiones ‘triángulo' y ‘ángulo', sino por relación a aquella proposición que en la evidencia nos concernía. Éste es un aspecto de la cuestión que es menester no perder de vista.

Se podría creer que esas mismas proposiciones geométricas que habitualmente evidenciamos de la manera apuntada, pueden evidenciarse también en la forma de una deducción dentro de un sistema axiomático. Ahora bien, es un hecho que la necesidad de una proposición deductivamente derivada sólo puede mantenerse si los axiomas de los que parte la deducción son ellos mismos necesarios. Esto era así para Euclides, ciertamente, que asumía la necesidad de sus postulados. Esa situación se mantuvo históricamente durante mucho tiempo en sistemas que incorporaban leves modificaciones en la formulación.

10 Cf. Quine, W.V., «Two Dogmas of Empiricism», en Feigl, H., et. al. (eds.), Readings in Philosophical Analisys, New York, 1972, p.93. 
Ahora bien, los axiomas de esos sistemas eran tales que su necesidad se evidenciaba, de nuevo, dándonos cuenta de las posibilidades que caben para aquello de lo que significativamente tratamos, normalmente al hilo de ciertas representaciones, en una construcción operacional del tipo que antes precisamos. Hay que tener claro, por tanto, que lo que durante todo ese tiempo se estaba afirmando en esos axiomas eran aquellas proposiciones que se acreditaban en esas evidencias, y no otra cosa. Por eso, no es exacto decir que posteriormente se haya descubierto que en realidad el quinto postulado de Euclides no es necesario y que otras geometrías distintas a la euclidiana son posibles. El postulado de las paralelas es necesario porque lo que en él se afirma es la proposición que se evidencia al darse cuenta de las posibilidades dadas para las paralelas, habida cuenta que aquello de lo que significativamente tratamos con la expresión 'paralela' es lo que es en un arraigo de cosas determinado. Utilizar una expresión semejante al quinto postulado para formular algo distinto, a saber, algo que no se dice por relación al mismo orden de cosas y, por eso, que no involucra ya necesidad alguna, no es descubrir que ese postulado no expresaba en realidad algo necesario, sino modificar el postulado.

Reteniendo todo lo que se acaba de apuntar, podemos hacernos cargo ya del sentido que tendría un sistema axiomático del tipo que Hilbert desarrolló en Los Fundamentos de la Geometría. Suele decirse que Hilbert axiomatizó la geometría euclidiana en una estructura matemática en la que los términos utilizados poseen una definición implícita independiente de todo soporte intuitivo. En ese sistema, que marcó la concepción de los sistemas axiomáticos modernos, no hay evidencia para los axiomas, sino para el despliegue consecuente de las reglas del sistema. Quizá por eso mismo a veces se dice que las conexiones de la geometría euclidiana están exhibidas aquí de una manera puramente matemática. Esta manera de hablar puede, sin embargo, llevar a confusión. Justamente en ese sistema no tenemos ya evidencia de que la suma de los ángulos de un triangulo sea necesariamente 180 grados, sino evidencia de que en nuestro sistema se puede derivar una relación entre algo llamado 'ángulo', y algo llamado 'triangulo'. Y en otro sistema axiomático distinto podemos derivar una relación distinta para algo llamado ‘ángulo' y algo llamado ‘triangulo'. La estructura matemática de Hilbert no es, en realidad, una axiomatización de la geometría Euclidiana, porque no habla de lo mismo que ella. Las proposiciones que hace la geometría Euclidiana corresponden a una cierta evidencia. En el sistema de Hilbert, usando términos parecidos a los habitualmente empleados en la geometría Euclidiana, se derivan operacionalmente cosas que involucran una evidencia distinta. Entre lo uno y lo otro se puede estipular una correspondencia externa, sintáctica, pero eso no quita que en un caso se esté diciendo algo distinto que en el otro, a saber, que en un caso se esté diciendo algo necesario y en el otro no. La verdad acreditada al evidenciar que los ángulos de un triángulo suman necesariamente 180 grados difícilmente podría verse amenazada por un sistema matemático del tipo que Hilbert desarrolla habida cuenta de que aquí no encontramos siquiera la proposición cuya verdad aseverábamos.

Básicamente por el mismo motivo que venimos comentando carecería de todo sentido cuestionar la verdad de esa proposición aduciendo que al hilo de un cierto proceso de conocimiento empírico se ha desarrollado una teoría física que utiliza el aparato matemático de la geometría de Riemann. Quien así hace confunde cosas a fortiori distintas. Cuando evidenciamos que los ángulos de un triángulo suman necesariamente 180 grados no estamos acreditando una relación empírica a través de un procedimiento de medida en un contexto 
teórico que ha asumido ciertos invariantes físicos ${ }^{11}$. Se trata, simplemente, de otra cosa. Aquí, como antes, sólo se produce la apariencia de recusar una necesidad evidenciada modificando aquello de lo que se estaba tratando en esa evidencia.

En el sentido fijado en el punto anterior podemos, pues, afirmar: algo necesario, algo evidenciable en una construcción operacional, algo verdadero en todo mundo posible, es algo absolutamente verdadero.

\section{Necesidad sin esencialismo}

De manera esquemática se puede decir que el esencialismo es aquella posición que sostiene que, dado un individuo $\mathrm{x}$, algunas propiedades le pertenecen de manera accidental y otras de manera esencial. Ciertamente, a nosotros no se nos ocurriría sostener nada parecido a que algo es esencial a un individuo en tanto que individuo. Pero tampoco creemos que la comprensión de la necesidad que aquí se ha expuesto pueda ser acusada de esencialismo. Si podemos evidenciar que algo coloreado es necesariamente extenso eso se debe a que al hablar de algo coloreado no nos estamos refiriendo a un cierto individuo, ni a un conjunto de individuos, sino a cualquier cosa coloreada. La expresión 'algo coloreado' no se está usando entonces para nombrar individuos, ni para designar una clase de individuos, sino para discriminar algo que nos concierne en nuestro mundo. Por eso, lo que en la evidencia de esa proposición tiene que advertirse no es lo que a ciertos individuos es esencial, sino lo que cabe y no cabe por relación a aquello de lo que significativamente se está tratando. De la misma manera, si yo pudiera evidenciar que un hombre necesariamente carece de escamas, eso no se debería a que a ciertos individuos denominados 'hombres' les estaría resultando esencial carecer de escamas. Se debería a que usando la expresión «hombre» en mi mundo tal y como la uso aquello que estoy discriminando con la expresión 'hombre' es tal que bajo ello no cabría la posibilidad de algo con escamas. Ciertamente, si alguien usara la expresión 'hombre' para significar otra cosa, podría utilizar la expresión 'un hombre carece necesariamente de escamas' para decir algo falso. Pero sería falso porque sería una proposición distinta de la que yo había evidenciado como necesaria.

Como se ve, el reparo de esencialismo se diluye inmediatamente cuando la necesidad se capta adecuadamente. No hay construcción operacional por relación a individuos y, por ello, no hay algo necesario por relación a un individuo como individuo. Que el esencialismo se

11 Para establecer una geometría para el mundo físico es necesario decidir, entre otras cosas, qué elementos se toman como irreducibles. En la teoría de la relatividad, por ejemplo, se postulan criterios absolutos de congruencia espacial para «cuerpos rígidos». Estos criterios no se introducen aleatoriamente, pues están guiados por principios regulativos como la simplicidad y homogeneidad de la teoría física que no son empíricamente descriptivos: se introducen «a priori». Teorías físicas con la misma adecuación empírica y poder predictivo pueden dar lugar a diferentes concepciones geométricas del mundo. La decisión entre ellas no se hace en términos de adecuación empírica. Exposiciones clásicas de todo esto pueden encontrarse en JAMMER, M., Concepts of Space, New York, Dover Publications, 1993, pp.172-173; Von HelmHoltz, H., «On the Origin and Significance of Geometrical Axioms» en Philosophy of Science, the Historical Background, J. Kockelmans (ed.), The Free Press, 1968, pp.130-131; PoINCARÉ, H., «Non-Euclidean Geometries and the Non-Euclidean World», en Feigl H. and Brodbeck M. (eds), Readings in the Philosophy of Science, University of Minnesota, 1953, p.180; EINSTEIN, A., «Geometry and Experience» in Feigl H. and Brodbeck M. (eds), op. cit., p.192; REICHENBACH, H., The Philosophy of Space and Time, New York, Dover Publications, 1958, pp.14-19, 30-37. 
considere todavía como un obstáculo importante en el intento de elucidar la modalidad de necesidad se explica en parte por lo extendida que está la creencia de que un análisis lógico formal es la vía por la que debe alcanzarse esa elucidación. Precisaré a continuación lo que quiero decir con esto.

Usando un aparato lógico estándar junto con los operadores $\square$ y $\diamond$, en el siglo XX se han construido varios sistemas lógicos orientados a formalizar las inferencias modales que realizamos en el lenguaje común. Los esfuerzos de Carnap en el desarrollo de las lógicas modales fueron proseguidos sobre todo por Kripke y Hintikka ${ }^{12}$. Se desarrollaron entonces interpretaciones semánticas que se inspiraban lejanamente en la idea de Leibniz que hacía corresponder verdad necesaria y verdad en todo mundo posible. Por supuesto, a la hora de dar una interpretación semántica de un cálculo sintácticamente definido uno es libre de elegir los dominios de interpretación y los objetos constitutivos del modo que mejor le parezca. El buen sentido del sistema lógico no tiene por qué mezclarse con el sentido que quepa o no quepa dar al enunciado pre-lógico que identifica verdad necesaria y verdad en todo mundo posible. Ahora bien, si se cree que la interpretación de nuestro cálculo constituye una formalización que corresponde adecuadamente a las inferencias modales que naturalmente realizamos, entonces llamar 'es necesario' al operador $\square$, llamar 'es posible' al operador $\diamond$ y llamar 'mundos posibles' a los elementos de un conjunto respecto a los cuales se ha hecho relativa la verdad definida en esa interpretación, pasa a ser algo más que una mera cuestión de nombres. Para que esa creencia se mantenga es esencial creer que los mundos posibles de los que se habla pre-lógicamente cuando se iguala verdad necesaria y verdad en todo mundo posible deben ser algo así como una pluralidad de individuos determinados por ciertas propiedades. La interpretación semántica de un cálculo en términos de objetos (en el sentido apuntado) es característica del modus operandi lógico y, consecuentemente, sólo cabe asumir que las lógicas modales sean formalizaciones adecuadas de las inferencias naturales cuando se asume que verdad en todo mundo posible, como equivalente de verdad necesaria, es algo así como verdad que vale para toda pluralidad de individuos y estados de cosas objetivos. Que, por otra parte, esos ámbitos objetivos se interpreten de manera realista, como en Lewis ${ }^{13}$, como pluralidades de estados de cosas constatables que admiten o no constataciones actuales, como en Plantinga ${ }^{14}$, o como un conjunto de proposiciones máximamente consistentes, como en Adams ${ }^{15}$, es secundario y no tan importante. En todas esas interpretaciones el sintagma «verdad en todo mundo posible» se está comprendiendo, de entrada, dentro de la orientación objetiva que marca el modus operandi lógico. Ahora bien, allí donde la comprensión de la necesidad se ha vinculado de entrada a lo individual-objetivo, tiene que surgir el problema del esencialismo y el problema de la identidad trans-mundana como escollos insalvables.

12 Cf. Kripke, S., «Semantical Considerations on Modal Logic', en Linsky, L. (ed.) Reference and Modality, Oxford, 1971; Hintikaa, J., «Models of Modality», en Loux, M. J. (ed.), The Possible and the Actual, Cornell, 1979.

13 Cf. Lewis, D., Counterfactuals, Harvard, 1975, pp.84-91.

14 Cf. Plantinga, A., «Actualism and Possible Worlds» en Loux, M.J. (ed.), The Possible and the Actual, Cornell, 1979, 237-252.

15 Cf. Adams, R. M., «Theories of Actuality», en Loux, op. cit., p.190ss. 
En este artículo se ha sostenido que una verdad necesaria es una verdad evidenciable en una construcción operacional, con independencia de constataciones fácticas. Ahora, si se desea considerar equivalentes los sintagmas «verdad necesaria»y «verdad en todo mundo posible», esto último no puede ser entendido como «fácticamente verdadero en cualquier ámbito objetivo posible», sino en el sentido de verdadero en una evidencia auto-contenida, con independencia de toda facticidad. Esta comprensión de la necesidad prescinde de la referencia a individuos y estados de cosas objetivos y, ciertamente, no contribuye a la formalización de las inferencias modales. Pero esto no es para nosotros una deficiencia. No lo es porque nos parece que el problema de fondo es, más bien, creer que una formalización lógico-objetiva es la vía para aclarar la necesidad de la que habitualmente hablamos.

Algunos protestarán que sin el anclaje en referencias objetivas cualquier tratamiento de la necesidad no puede aclarar nada, pues ha de limitarse a sugerir hechos mentales, subjetivos. Si la verdad necesaria no es algo primariamente ligado a individuos y estados de cosas objetivos, sino relativo a aquello que en cada caso pensamos, no habrá en el fondo tal verdad necesaria sino sólo algo subjetivamente dado para un agente pensante en un momento particular ${ }^{16}$. A esta objeción respondemos brevemente: 1. Que la contraposición que aquí se está marcando entre lo mental-subjetivo y lo real-objetivo es deudora de una categorización ontológica no aclarada, que ha introducido la objeción, no nuestras consideraciones. 2. Que no asumimos que la evidencia operacional de algo necesario sea algo así como un estado «mental-subjetivo». Aquí se ha tratado de matizar esa evidencia en su concreción experiencial, sin formalizarla ontológicamente o interpretarla desde otro lugar. 3. Que la necesidad acreditada en esa experiencia es efectivamente absoluta y que ese carácter absoluto, tan familiar, lejos de quedar garantizado, es el que justamente se nos va de las manos cuando se comprende la verdad necesaria como relativa a ámbitos de individuos y estados de cosas subsistentes. 4. Que nuestro trabajo no buscaba defender ninguna «tesis» sobre la necesidad, o dar la «definición adecuada»sobre la necesidad, sino ayudar a que el lector se diera cuenta de la experiencia concreta que nos legitima a hablar habitualmente de verdad necesaria. 5. Que la apelación a lo objetivo como principio dilucidatorio debería legitimarse de una manera concreta, no circular, para que la objeción fuera otra cosa que expresión de esa metodología objetivista cuyas carencias en la cuestión tratada se acaban de apuntar.

16 Cf. Rescher, «The Ontology of the Possible», en Loux, op. cit., p.166ss. 